\title{
A Teologia como sinal de esperança diante da Pandemia
}

\author{
Theology as a sign of hope facing of pandemic
}

Diego Nascimento Silva

\section{Resumo}

O mundo sempre foi assolado por doenças que devastaram regiões e, muitas vezes, se propagaram por diversos países, tornando-se grandes epidemias que ceifaram milhões de vidas. No assombro do medo e da insegurança diante das pandemias, o ser humano sempre se inclinou para buscar respostas na religião, ora achando que tais doenças eram castigos divinos, ora praticando atos penitenciais para afugentar as pestes. Desde o final de 2019, o mundo se vê novamente devastado, agora pela pandemia da Covid-19, o que gerou grande dor e desespero nos povos e nações. Diante desse quadro, a atual reflexão teológica pode ajudar as pessoas a evitar o erro de creditar a Deus a culpa pela doença e iluminar os caminhos para que a fé sustente a esperança da humanidade que se vê em um barco agitado pelas ondas e pelos ventos da pandemia.

Palavras-chave: Pandemia. Teologia. Deus. Esperança.

\section{Abstract}

The world has always been plagued by diseases that devastated regions and many times spread through several countries, becoming major worldwide epidemics that claimed millions of lives. Overwhelmed by fear and insecurity when facing pandemics, humans always looked for answers in religion, sometimes thinking that such diseases were divine punishments or sometimes practicing penitential acts to scare away the pests. Since 2019, the world was again devastated, now by the Covid-19 pandemic, resulting in great pain and 
despair in people's lives and nations. Given this situation, current theological reflection can help people avoid the mistake of blaming God for the disease and illuminate the paths for faith to sustain the hope of humanity that sees itself in a boat shaken by the waves and winds of pandemic.

Keywords: Pandemic. Theology. God. Hope.

\section{Introdução}

A pandemia da Covid-19 ainda não acabou, vacinas estão sendo desenvolvidas e, em diversos países, e a campanha de vacinação encontra-se em curso. Não se pode negar que elas se tornaram uma esperança na guerra contra o vírus que, no campo de batalha, parecia ser invencível.

Embora essa não seja a primeira pandemia enfrentada pela humanidade, não deixa de ser devastadora e assustadora, pois, diante do vírus mortal, todos os avanços científicos se mostraram insuficientes para conter a propagação e salvar vidas. Junto a isso se acrescenta a forte corrente negacionista que, além de tratar a doença com descaso, incentivou outros a fazerem o mesmo, principalmente a não seguir as orientações básicas como usar máscara, manter o distanciamento social, higienizar as mãos e os objetos com álcool em gel e evitar aglomerações.

Infelizmente, o mau exemplo de governantes e de boa parte da população fez com que o vírus continuasse a se propagar e a fazer vítimas. No campo religioso não foi diferente: alguns pastores evangélicos e padres pregaram que a fé era a melhor e única forma de não contrair a doença; outros, seguindo pensamentos de séculos anteriores, usaram do discurso do castigo divino como meio para alienar ainda mais as pessoas que já estavam sofrendo com toda a insegurança gerada pela pandemia.

Diante desse triste quadro, a atual reflexão teológica tem a missão de não apenas mostrar que a culpa dos males enfrentados pela humanidade não é de Deus, mas também de salientar que Ele, por meio de Seu Filho Jesus de Nazaré, faz-se presente no meio da humanidade, caminha junto, sustenta nos momentos difíceis e, como tal, fortalece a fé e a esperança no coração de todos.

O presente artigo visa traçar um panorama geral da situação em que se encontra a humanidade, buscando apontar àquela que insiste em brilhar no meio das trevas: a esperança. Por isso, mesmo agitados pelos ventos da pandemia, 
seguros de que Deus está ao lado, todos podem dizer como o Apóstolo Paulo: "somos afligidos de todos os lados, mas não vencidos pela angústia" $(2$ Cor 4,8).

\section{Breve histórico das doenças que devastaram o mundo}

A pandemia que, no final de 2019 e em todo o ano de 2020, alastrou-se pelo mundo, ceifando milhares de vidas, não foi a única na história e, possivelmente, não será a última a ser enfrentada pelo ser humano. Quanto mais globalizado o mundo, mais facilmente as doenças que atingem uma região se propagarão pelo demais países, como bem salientou Martins, ao afirmar que "epidemias fazem parte da realidade de um mundo cada vez mais globalizado, gerando uma série de sensibilidades e vulnerabilidades biológicas aos Estados Nacionais que eventualmente podem muito rapidamente se tornar em pandemias internacionais". ${ }^{1}$

Inúmeras foram as doenças que arrasaram regiões e povos. Dentre essas, a própria história destaca a peste negra do século XIV que, durante 20 anos, levou à morte mais de 50 milhões de pessoas. Dessa epidemia, ficou marcado na história o uso, pelos médicos, de uma roupa própria para lidar com os doentes e de uma máscara com formato de bico, não apenas para ajudar a se proteger do cheiro forte e repugnante que pairava no ar, mas também para evitar o contato que gerava a propagação da doença.

No ano de 1918, o mundo, com o movimento das tropas no período da I Guerra Mundial, era atingindo pela pandemia que ficou conhecida como a "gripe espanhola", levando mais de 100 milhões de pessoas a óbito. Não se pode esquecer também da varíola que, por mais de 3 mil anos, ceifou milhões de vidas, peste que devastou a cidade de Atenas em 430-429 a.C; além da peste bubônica, que atingiu a Inglaterra no final do século XVII.

Atingiu todas as pessoas de tal forma que as cidades eram isoladas em quarentenas; as pessoas que tivessem a peste em casa eram assinaladas com uma cruz na porta, era colocada uma oração na porta para que Deus apiedasse de suas almas. O Estado, curiosamente, providenciava comida e entregava pelas janelas ou frestas das portas. Era proibido sair de casa. Era uma quarentena forçada e policial que procurava evitar a disseminação da peste; ainda que não se soubesse, naquele momento, que o agente difusor, o rato, continuava ignorando a quarentena. ${ }^{2}$

\footnotetext{
${ }^{1}$ SENHORAS, E. M., Coronavírus e o papel das pandemias na história humana, p. 35.

${ }^{2}$ KARNAL, L., Epidemias, história e o novo normal.
} 
Mais proximamente, em 2009, o mundo se viu novamente assolado por uma epidemia, denominada gripe suína (H1N1), infectando mais de 200 mil pessoas em todo o mundo e deixando um rastro de mais de 18 mil mortos. Hoje, diferentemente dos tempos antigos, conta-se com os avanços tecnológicos e científicos, como também com a organização e comunicação entre os países do mundo que ajudam no combate de doenças que trazem em si um potencial para se tornarem grandes pandemias, como no caso do Ebola, do zika vírus e de outros.

Todavia, vale recordar que, no advento dessas pandemias, surgiram grupos religiosos fanáticos que atribuíram à ira de Deus tais acontecimentos, como, por exemplo, aquelas pessoas que praticavam autoflagelação como forma de sacrifícios e penitências. Tais práticas foram condenadas, na época da peste negra, pelo Papa Clemente VI.

Diante de um mal que assombra a humanidade, ontem e hoje, a resposta metafísica é muito buscada para não apenas responder ao drama, mas também como uma forma de exercer controle e domínio sobre as pessoas pelo medo e pelo terror. No que se refere às pandemias, como salientou, em um texto, Daniel Defoe, autor do livro o diário do ano da peste, "a peste é um inimigo formidável, armado com terrores a que um homem não está suficientemente preparado para resistir ou lutar". ${ }^{3}$ Assim, diante de tais sofrimentos, a humanidade tende sempre a buscar uma resposta, creditando a culpa dos males sofridos em algo ou alguém.

\section{A culpa seria de Deus? A reposta da Teologia diante da Pandemia da Covid-19}

"Vós nos destes a comer o pão das lágrimas, e a beber destes um pranto copioso" (S1 80,6). As palavras deste salmo parecem ser as palavras de muitos hoje, que estão desolados e perdidos na fé diante do mal da Covid-19 que devasta o mundo. Quando se acha que já se sabe o essencial do vírus para combatê-lo, de repente, descobre-se uma nova cepa tão perigosa e mortal quanto a primeira.

Embora muitos países, inclusive o Brasil, tenham diminuído as restrições e o isolamento, os casos de infecções pelo novo coronavírus estão crescendo, os hospitais estão ficando novamente lotados e os casos de óbitos subindo assustadoramente. Diante desse quadro terrível, uma esperança despontou no horizonte: as vacinas já desenvolvidas e aplicadas em muitos países dão, em

${ }^{3}$ DEFOE, D., apud MARTINS, C. M., Peste e literatura, p. 16. 
certa medida, um ânimo e um conforto, como se lê no Sl 126,6: "os que semeiam entre lágrimas, com alegria colherão".

Deus, em seu amor onipotente, não provoca, nem "permite", nem pode parar uma pandemia com um "passe de mágica". Porque mesmo a onipotência de Deus encontra limites diante da estupidez humana e de uma liberdade humana irresponsável, que continuam se manifestando assustadoramente nestes tempos de pandemia. ${ }^{4}$

A situação em que vive a humanidade mostrou que "bastou o menor e mais informe elemento da natureza, um vírus, para nos recordar que somos mortais, que o poderio militar e a tecnologia não bastam para nos salvar". ${ }^{5}$ Todos os avanços tecnológicos e científicos não foram suficientes para barrar a propagação e a perda de milhares de vidas.

A humanidade, dilacerada pelas divisões políticas e religiosas, viu-se diante de um inimigo comum que não respeita idade, classe social, religião ou gênero; e que colocou em xeque todas as nossas noções de relacionamento e de convivência como seres racionais abertos ao outro.

$\mathrm{O}$ vírus não tem rosto, é insidioso. Infiltra-se pela mão mal lavada, um toque no rosto, um gesto distraído nos cabelos. Alia-se aos gestos mais cotidianos e normais: a maçaneta aberta, o botão do elevador pressionado. Ou mais ainda nos gestos afetivos: apertos de mão, abraços, beijos, tudo que aproxima, conforta e afaga os corpos e corações humanos. Diziam primeiro que era mais inofensivo que as gripes anteriores, depois percebeuse que na verdade não era assim. Assaltou violentamente nossos mais inofensivos desejos: estar juntos, conversar, partilhar comida e bebida, divertir-se. Feriu de morte tudo que é lazer: festas, reuniões, eventos. De repente o inimigo sem rosto, se não estava já instalado no próprio corpo, alojava-se ameaçadoramente no corpo do outro. ${ }^{6}$

Diante de todo o cenário desolador provocado pela propagação mundial do vírus, as pessoas foram jogadas num "oceano" de inseguranças, seja no campo da saúde física e mental, seja na economia e na política. Atitudes dos governos, que tentaram minimizar os impactos da pandemia, foram como que ondas fortes a agitar mais ainda as "águas" nas quais as pessoas estavam submersas. No Brasil, não apenas se acompanhou a falta de uma ação concreta

\footnotetext{
${ }^{4}$ SBARDELOTTO, M., Nenhuma pandemia vem de Deus.

${ }^{5}$ CATALAMESSA. R., Pregação da sexta-feira Santa.

${ }^{6}$ BINGEMER, M. C., Relacionalidade.
} 
para o combate da pandemia pelo governo Federal, como também se assistiu essa triste realidade se tornar uma questão de guerra política em vista das eleições futuras.

Um governo que se volta para o desmonte do Estado brasileiro, que se omite em meio à pandemia, assumindo postura negacionista, se omitindo em relação às suas responsabilidades, adotando atitudes enganosas $\mathrm{e}$ desinformadas na comunicação com a população. A estrutura de governança do Sistema Único de Saúde (SUS), desenvolvida com sucesso ao longo de muitos anos, foi deixada de lado numa intencional e inexplicável ação governamental que parece querer deixar a epidemia seguir o seu curso quase que natural. ${ }^{7}$

Sendo parte integrante da vida em sociedade, como também de milhões de pessoas, a religião foi duramente atingida pelo caos gerado na pandemia. Com as regras de isolamento, distanciamento e fechamento de estabelecimentos, as Igrejas tiveram de cancelar seus eventos, seus encontros, seus cultos e suas reuniões. Obviamente, em nome de Deus e da liberdade religiosa, alguns líderes religiosos se levantaram contra estas medidas, defendendo que quem tem fé jamais seria infectado pelo vírus.

Não são poucos os que hoje estão abandonando a fé, pois, no fundo, nunca experimentaram que Deus podia ser para eles fonte de vida e de alegria. Ao contrário, estes sempre sentiram a realidade como estorvo de vida. Neles restou a lembrança de um cristianismo que tem pouco a ver com a felicidade que buscam do mais profundo de seu ser. [...]. estas pessoas deveriam experimentar que a fé faz bem, que é bom crer, que Jesus Cristo é o melhor estímulo e a força mais vigorosa para viver de maneira positiva e acertada. ${ }^{8}$

No campo católico, surgiu um movimento, que se espalhou em vários lugares do mundo, denominado "Devolvam-nos a missa", que atacava bispos e padres, como se o fechamento das igrejas fosse uma escolha exclusiva deles e não a consequência de várias medidas tomadas no combate ao vírus.

É como se, de um pedestal de superioridade moral, eles nos dissessem: "bispos covardes que tiraram a missa de nós, agora devem nos devolvêlas". Essa é uma mentira terrível, longe da realidade, causada quando a

7 TRAVASSOS, C., A investigação em serviços de saúde e a pandemia de COVID-19.

${ }^{8}$ PAGOLA, J. A., É bom crer em Jesus, p. 9. 
ideia é superior à realidade (ideologia). A celebração pública do culto não foi tirada de nós pelos bispos. Foi suspenso por toda a comunidade, e não por covardia de ninguém, mas por um critério de prudência para cuidar do valor absoluto da vida de todos. Estamos no meio de uma pandemia! ${ }^{9}$

A situação fica ainda mais estranha quando se percebe que os que brigaram e exigiam o retorno imediato das celebrações eucarísticas são os mesmos que acusam de heresias aqueles que pensam em soluções, como no caso dos viri probati ou da ordenação feminina como formas se resolver a privação de tantos cristãos católicos que, de modo especial na região da Amazônia, ficam anos e anos sem a Eucaristia por falta de ministros ordenados.

O triste e o dificultoso é que, essas mesmas pessoas que hoje choram e lamentam o distanciamento da participação na eucaristia (são leigos, leigas, religiosos, religiosas, padres e bispos) foram e são os primeiros opositores para que se solucione essa privação do banquete a que são submetidos milhões de irmãos e irmãs na extensa e longínqua Amazônia. Ficam profundamente indignados quando, para fazer chegar o pão da vida, essas comunidades se dispõem a encontrar soluções e se sentem desfiadas a falar em nome da Tradição dizendo que isso seria romper com a possibilidade de mantermos a Igreja como quis Jesus. ${ }^{10}$

Todos esses conflitos não apenas criam feridas na Igreja, mas, neste momento difícil pelo qual passa a humanidade, deixam as pessoas desorientadas, inseguras e, por vezes, sentindo-se abandonadas pelo próprio Deus.

Nesse cenário obscuro e triste, a Teologia deve ser uma ferramenta de reflexão que alimenta e fortalece a esperança. Por isso, vale sempre lembrar que "para nós, a teologia não consiste somente em ideias, discursos e altas elucubrações. Ela tem suas raízes na realidade concreta". ${ }^{11}$

Para a Teologia Cristã, o coração de sua reflexão é o próprio Jesus Cristo que, como ensina a Carta aos Hebreus, foi "em tudo semelhante a nós, exceto no pecado" $(4,15)$. Nesse sentindo, a Teologia tem a missão de trazer Jesus para perto das pessoas, sobretudo neste tempo de dor e isolamento social.

Desejo ardentemente que, neste tempo que nos cabe viver, reconhecendo a dignidade de cada pessoa humana, possamos fazer renascer, entre

\footnotetext{
${ }^{9}$ ROSAS, J. A. R., Organizadores do "Devolvam-nos a missa" são os mesmos que atacam bispos.

${ }^{10}$ FERNANDES, L. A., A impossibilidade provisória e a permanente.

${ }^{11}$ BRITO, A. I. A., Apresentação, p. 1.
} 
todos, um anseio mundial de fraternidade. [...]. Sonhemos com uma única humanidade, como caminhantes da mesma carne humana, como filhos desta terra que nos alberga a todos, cada qual com a riqueza da sua fé ou das suas convicções, cada qual com a própria voz, mas todos irmãos. ${ }^{12}$

As iniciativas que foram tomadas, como transmissão de missas pelas redes sociais, grupos de orações, terços e diversos encontros espirituais que foram realizados em forma online. Tais iniciativas, nos meses em que fomos exortados a permanecer em nossas casas para salvaguardar a nossa vida e a dos nossos irmãos e irmãs, foram importantes para confortar, animar e ajudar a muitos que, na pandemia, se sentiram perdidos e sem rumo.

O Concílio Vaticano II (1962-1965), na Constituição Pastoral Gaudium et Spes, afirmou que "as alegrias e as esperanças, as tristezas e as angústias dos homens de hoje, sobretudo dos pobres e de todos que sofrem, são também as alegrias e as esperanças, as tristezas e as angústias dos discípulos de Cristo". ${ }^{13}$ Isso significa que a Igreja não é e jamais poderá ser indiferente aos sofrimentos da humanidade; pelo contrário, como sacramento do Reino de Deus, cabe à Igreja, com sua Teologia, sua espiritualidade e suas ações práticas iluminar, com o Evangelho, as trevas que cobrem os povos. Neste tempo de pandemia, a Igreja precisa abraçar sua missão e se fazer próxima das pessoas, de modo especial dos pobres, que são esquecidos pelos poderes públicos. Nesse sentido, vale lembrar o que disse o Papa Francisco na primeira oração do Angelus, depois do confinamento imposto no dia 08 de março de 2020:

É um pouco estranho esta oração do Angelus hoje, com o Papa "fechado" na biblioteca, mas eu vejo-vos, estou perto de vós. E gostaria também de começar por agradecer àquele grupo [presente na Praça] que se manifesta e luta "Pelos esquecidos do Idlib". Obrigado! Obrigado pelo que fazeis. Mas adotamos esta forma de recitar o Angelus hoje para respeitar as medicas precaucionais, a fim de evitar pequenas concentrações de pessoas, que podem favorecer a transmissão do vírus. ${ }^{14}$

Como também não recordar aquela sexta-feira da quaresma, 27 de março de 2020, quando, na Praça de São Pedro vazia e chuvosa, aquele homem idoso, pertencente ao grupo de risco, exortava, não apenas aos católicos, mas a todas as pessoas a não perderem a esperança e a confiarem em Jesus?

\footnotetext{
${ }^{12}$ FT 8.

${ }^{13}$ GS 1.

${ }^{14}$ FRANCISCO, PP., Angelus.
} 
"Ao entardecer..." $(M c 4,35)$ : assim começa o Evangelho, que ouvimos. Desde há semanas que parece o entardecer, parece cair a noite. Densas trevas cobriram as nossas praças, ruas e cidades; apoderaram-se das nossas vidas, enchendo tudo dum silêncio ensurdecedor e um vazio desolador, que paralisa tudo à sua passagem: pressente-se no ar, nota-se nos gestos, dizem-no os olhares. Revemo-nos temerosos e perdidos. À semelhança dos discípulos do Evangelho, fomos surpreendidos por uma tempestade inesperada e furibunda. [...]. O Senhor interpela-nos e, no meio da nossa tempestade, convida-nos a despertar e ativar a solidariedade e a esperança, capazes de dar solidez, apoio e significado a estas horas em que tudo parece naufragar. O Senhor desperta, para acordar e reanimar a nossa fé pascal. Temos uma âncora: na sua cruz, fomos salvos. Temos um leme: na sua cruz, fomos resgatados. Temos uma esperança: na sua cruz, fomos curados e abraçados, para que nada e ninguém nos separe do seu amor redentor. No meio deste isolamento que nos faz padecer a limitação de afetos e encontros e experimentar a falta de tantas coisas, ouçamos mais uma vez o anúncio que nos salva: Ele ressuscitou e vive ao nosso lado. Da sua cruz, o Senhor desafia-nos a encontrar a vida que nos espera, a olhar para aqueles que nos reclamam, a reforçar, reconhecer e incentivar a graça que mora em nós. Não apaguemos a mecha que ainda fumega (Is 42,3 ), que nunca adoece, e deixemos que reacenda a esperança. ${ }^{15}$

Infelizmente, muitos foram aqueles que, ao invés de reavivar a fé e a esperança diante desse drama que afeta toda a humanidade, deixaram-se afogar nas ondas do medo, do desespero e, imbuídos da ideia de onipotência divina que interfere em tudo, colocaram nas mãos de Deus a culpa por tal tragédia. E, não obstante a isso, ainda houve aqueles que agradeceram e afirmaram que a pandemia é uma ação de Deus para purificar, limpar e expurgar o mal do mundo.

Deus, ao contrário, exatamente neste momento, sofre conosco, especialmente com os mais frágeis e impotentes diante da Covid-19, dando-nos colo e ternura. Deus está neles, gemendo e gritando junto com eles contra a pandemia e contra as estruturas sociais, políticas e econômicas que impedem o enfrentamento do vírus. ${ }^{16}$

\footnotetext{
${ }^{15}$ FRANCISCO, PP., Momento extraordinário de oração em tempo de epidemia.

${ }^{16}$ SBARDELOTTO, M., Nenhuma pandemia vem de Deus.
} 
Mas a verdade é que, se a humanidade deseja realmente encontrar o ser responsável pelas mazelas e pelas tragédias que desfiguraram o mundo, basta olhar no espelho. O que se está fazendo com o planeta, os avanços tecnológicos, bélicos e econômicos que não respeitam a flora e a fauna, mas os veem como produtos a serem consumidos até a extinção, ao mesmo tempo em que dão a falsa impressão de evolução e modernização, constroem a própria destruição do ser humano. Não, Deus não é culpado pelo mal que atinge a humanidade.

A saúde que Jesus promove não consiste somente numa melhoria física. Sua ação vai além do simples fato de fazer retroceder uma enfermidade ou de eliminar um problema orgânico. [...]. A saúde que ele suscita não é fruto de um tratamento médico destinado a eliminar uma enfermidade, mas trata-se de uma cura mais profunda e total. [...]. Jesus liberta os enfermos de sua solidão e de seu isolamento interior; sua fé num Deus amigo da vida contagia a todos; faz despertar neles a confiança no Pai; perdoa seus pecados. ${ }^{17}$

Em 2020, e já em 2021, com todas as restrições, todos foram convidados a olhar para o que, na vida, é essencial e, embora muitas pessoas tenham corrido o risco da contaminação nos centros comerciais devido às aglomerações, principalmente na época das festas de final de ano (2020), o Natal em que se celebra o nascimento do Salvador, do Emanuel, Deus-conosco, fez olhar para além das trevas que cercam a humanidade e, por isso mesmo, os cristãos, mesmo com as dificuldades presentes, são homens e mulheres da esperança, pois "Ele enxugará toda lágrima dos seus olhos, pois nunca mais haverá morte, nem luto, nem clamor, e nem dor haverá mais. Sim! As coisas antigas se foram" (Ap 21, 4).

\section{Conclusão}

No ano de 2008, foi lançado um longa-metragem britânico intitulado God on Trial, que, na tradução, pode-se colocar como o julgamento de Deus. Nesse filme, Deus é colocado no banco dos réus para ser julgado sobre a culpa ou não das atrocidades realizadas pelos nazistas, de modo especial, contra os judeus.

Sem desejar dar spoiler do final da trama, o longa é importante para mostrar que a humanidade, não importa a época, sempre tem a tendência de buscar as respostas para os males sofridos nas explicações metafísicas. O problema dessa inclinação é que, por vezes, Deus é colocado como o ser divino

${ }^{17}$ PAGOLA, J. A., É bom crer em Jesus, p. 145. 
que tudo vê e, por isso mesmo, castiga a humanidade com pragas, doenças e calamidades. Quando não é essa a resposta, a outra mais propagada é que a fé não precisa caminhar unida com as orientações cientificas; é a tentação de cair no fideísmo que faz da fé uma ação cega, intolerante e fundamentalista.

Se é verdade que a resposta para o sofrimento não é simples de se oferecer, tampouco será encontrada nessas estradas que, na verdade, deixam os homens e as mulheres abandonados à própria sorte.

Por isso, a atual reflexão teológica, longe de se resumir a conceitos prontos e frios, precisa, no vendaval desta pandemia, mostrar a face do Deus que, em Jesus Cristo, mostrou-se cheio de ternura e misericórdia. Isso significa que, amparados pela fé, os homens e mulheres podem oferecer ao mundo exemplos que ajudem a outros a enfrentarem os desafios, obstáculos e medos que foram provocados pela pandemia da Covid-19 que devastou o mundo.

Ainda se vive tempos difíceis. A pandemia não acabou e, infelizmente, muitos ainda usam o nome de Deus para motivar explicações que, na realidade, são puramente humanas e marcadas por ideologias contrárias ao Evangelho. As sombras da morte, do medo e do desespero ainda rondam a vida e a convivência humana. Por isso, a Teologia, como fonte de água cristalina que irriga os corações, tem muito a fazer pelas pessoas, despertando e alimentado a esperança que nos faz enxergar além da dor e do sofrimento atuais. Por isso, a Teologia, imbuída da esperança, vai na direção oposta da disseminação de ideias, teorias e pensamentos de fracassos e desgraças apocalípticas.

Os compositores Ivan Lins e Vitor Martins, em plena ditadura militar (1979), compuseram uma belíssima canção que, certamente, pode expressar e indicar a esperança e o ânimo que devem ornar a vida, o coração e as ações de todos os que são responsáveis por transmitir a Palavra de Deus:

Desesperar jamais / Aprendemos muito nesses anos / Afinal de contas não tem cabimento / Entregar o jogo no primeiro tempo / Nada de correr da raia / Nada de morrer na praia / Nada! Nada! Nada de esquecer / No balanço de perdas e danos / Já tivemos muitos desenganos / Já tivemos muito que chorar / Mas agora, acho que chegou a hora/ De fazer valer o dito popular / Desesperar jamais. ${ }^{18}$

Nesses tempos em que a Pandemia ainda assola muitos lugares no mundo, a Teologia deve ser um estandarte que motiva a "esperar contra toda esperança" $(\mathrm{Rm} 4,18)$.

${ }^{18}$ IVAN LINS, Desesperar jamais. 


\section{Referências bibliográficas}

BINGEMER, M. C. Relacionalidade: as lições da pandemia. Jornal do Brasil, Rio de Janeiro, 26 mar. 2020. Disponível em: $<$ https://www.jb.com.br/pais/artigo/2020/03/1022992-relacionalidade--aslicoes-da-pandemia.html>. Acesso em: 29 dez. 2020.

BRITO, A. I. A. Apresentação. Vida Pastoral, v. 62, n. 337, p. 1, jan./fev. 2021. CATALAMESSA, R. Pregação da sexta-feira Santa 2020. VATICAN NEWS, Roma, $\quad 10$ abr. $2020 . \quad$ Disponível em: $<$ https://www.vaticannews.va/pt/vaticano/news/2020-04/pregacao-sexta-feirapaixao-raniero-cantalamessa-vaticano.html>. Acesso em: $30 \mathrm{dez} 2020$.

FERNANDES, L. A. A impossibilidade provisória e a permanente: reflexão sobre a negação do banquete eucarístico. Instituto Humanitas Unisinos, 16 abr. 2020. Disponível em: <http://www.ihu.unisinos.br/598063-aimpossibilidade-provisoria-e-a-permanente-reflexao-sobre-a-negacao-dobanquete-eucaristico>. Aceso em: 29 dez. 2020.

FRANCISCO, PP. Angelus. Domingo, 8 de março de 2020. Disponível em: $<$ http://www.vatican.va/content/francesco/pt/angelus/2020/documents/papafrancesco_angelus_20200308.html>. Acesso em: $30 \mathrm{dez} .2020$.

FRANCISCO, PP. Fratelli Tutti: Sobre a fraternidade e a amizade social. São Paulo: Paulinas, 2020.

FRANCISCO, PP. Momento extraordinário de oração em tempo de epidemia. Disponível em: $<$ http://www.vatican.va/content/francesco/pt/homilies/2020/documents/papafrancesco_20200327_omelia-epidemia.html>. Acesso em: 29 dez. 2020.

IVAN LINS. Desesperar jamais. I. Lins, V. Martins [Compositores]. In: IVAN LINS. A Noite. [S.1.]: EMI, 1979. 1 LP (ca. 36 min.). Lado A. Faixa 1 (3 min. 32 s.). Disponível em: <https://www.letras.mus.br/ivan-lins/258963/>. Acesso em: 14 mar. 2021.

KARNAL, L. Epidemias, história e o novo normal. Café Filosófico, 23 abr. 2020. Disponível em: <https://www.youtube.com/watch?v=3UqlctQ6N7c>. Acesso em: 28 dez. 2020.

MARTINS, C. M. Peste e literatura: a construção narrativa de uma catástrofe. Portugal, 2011. 16p. Dissertação. Faculdade de Letras, Universidade de 
Coimbra.

Disponível

em:

$<$ https://estudogeral.sib.uc.pt/bitstream/10316/19317/1/Tese\%20da\%20Peste. pdf>. Acesso em: 29 dez. 2020.

PAGOLA, J. A. É bom crer em Jesus. Petrópolis, RJ: Vozes, 2016.

ROSAS, J. A. R. Organizadores do "Devolvam-nos a missa" são os mesmos que atacam bispos. Dom Total, 29 abr. 2020. Disponível em: $<$ https://domtotal.com/noticia/1440609/2020/04/organizadores-do-devolvamnos-a-missa-sao-os-mesmos-que-atacam-bispos>. Acesso em: 29 dez. 2020.

SBARDElOTTO, M. Nenhuma pandemia vem de Deus. Disponível em: $<$ https://pascombrasil.org.br/nenhuma-pandemia-vem-de-deus/ $>$. Acesso em: 15 mar. 2021.

SENHORAS, E. M. Coronavírus e o papel das pandemias na história humana. Boletim de Conjuntura, v. 1, n. 1, p. 35, 2020. Disponível em: $<$ https://revista.ufrr.br/boca/article/view/Eloi > . Acesso em: 28 dez. 2020.

TRAVASSOS, C. A investigação em serviços de saúde e a pandemia de COVID19. Cad. Sáude Pública, v. 36, n. 9, set. 2020. Disponível em: $<$ https://www.scielosp.org/article/csp/2020.v36n9/e00243920/pt/\#>. Acesso em: 30 dez. 2020.

VATICANO II. Gaudium et Spes. In: CONCÍLIO VATICANO II. Compêndio do Vaticano II: constituições, decretos, declarações. Petrópolis, RJ: Vozes, 2000. p. 143-256.

\section{Diego Nascimento Silva}

Mestrando em Teologia na Pontifícia Universidade Católica de São Paulo

São Paulo /SP - Brasil E-mail: semdiego91@gmail.com

Recebido em: 01/02/2021

Aprovado em: 26/06/2021 